\title{
Field Testing of an Ataxia Scoring and Staging System
}

\author{
EMMANUELLE POURCHER and ANDRÉ BARBEAU
}

SUMMARY: The authors present a simple sl'stem for disability scoring and functional staging of an ataxic patient, based on modifications of a previous scheme advocated by De Falco and collaborators (1979). This system was tested under field conditions in 47 ataxic subjects and found to be useful and functional.

RÉSUMÉ: Les auteurs présentent un système simple pour la quantification et la classification fonctionnelle d'un patient ataxique. Ce système est basé sur des modifications du schéma publié en 1979 par De Falco et collaborateurs. Notre système fut vérifié dans des conditions d'expédition sur place chez 47 patients ataxiques et trouvé utile et adéquat.
From the Department of Neurobiology, Clinical Research Institute of Montreal.

Reprint request for the complete supplement (phase three): Dr. André Barbeau, Clinical Research, Institute of Montreal, 110 Pine Avenue West. Montreal, Quebec, Canada, H2W IR7.
Two of the most difficult problems facing the clinician in the field of ataxia are those of classification and the various phenotypic presentations and quantification of the signs and symptoms observed. Such grading and staging systems have been utilized with success for disorders of the basal ganglia (Hoehn and Yahr, 1967) and have permitted the evaluation of new therapeutic approaches with objective data. Unfortunately, such systems did not exist for ataxic disorders until recently. In 1979, De Falco et al, proposed a workable system which they tested in their own patients of Southern Italy. The purpose of the present study was to test the workability of this system during investigations of ataxic patients in their homes and far from the research clinic. Experience with the De Falco scheme led to modifications which were also tested and will be detailed.

\section{SUBJECTS AND METHODS}

During a two week period in the month of July 1980, on the occasion of our yearly field investigation of ataxic patients, a total of 47 subjects ( 26 men; 21 women) were studied by a team of two neurologists (E.P. and A.B.). The type of ataxics involved are listed in Table One. Four patients had all the symptoms of typical Friedreich's ataxia as described by Geoffroy et al (1976). Three suffered from what we have termed "Ataxia of Beauce" (Barbeau, 1980). These patients had a recessive disorder characterized by gait and truncal ataxia with pyramidal tract deficits and no signs of posterior column involvement. It will be noted that, until the biochemical marker is known, we have elected to assign geographic names to the phenotypic subtypes examined. This takes into account the genetic and geographic isolate factors often encountered. Two patients had olivo-cerebellar atrophies (OPCA) of a recessive type, mainly characterized by speech disorders and gait ataxia (so called Matane type). Twenty patients suffered from a dominant form of olivo-ponto-cerebellar atrophy found in the Gaspé peninsula and previously reported by us (Wastiaux et al, 1978). The other 18 patients were examined in Minneapolis through the courtesy of Dr. Larry Schut, during a yearly follow up clinic of the National Ataxia Foundation. They included one female patient with the Sanger-Brown variant of OPCA (spasticity and macular degeneration), two OPCA type I (Konigsmark and Weiner, 1970) from Wyoming and 15 members of the well known SchutSwier OPCA family (Schut 1950, Landis et al, 1974) including 5 asymptomatic at risk subjects, and 10 clear-cut ataxics.

All patients were examined at home (or at the Minneapolis Clinic) by the two neurologists working as a team. While one carried out a standard neurological examination, the other one qualified every symptom and sign on a 0 to 3 scale $(0=$ normal, $1=$ slight $; 2$ $=$ moderate and $3=$ severe disability) and simultaneously with the scale reported by De Falco et al (1979). Both neurologists then decided on the functional stage to ascribe to each patient based on a scheme modified from De Falco et al (1979) and listed in Table 2.

\section{RESULTS AND DISCUSSION}

All 47 patients kindly collaborated in this detailed examination procedure. The initial evaluation of the data was based on the exact reproduction of the scheme developed by the Italian authors. This scheme lists 26 scored items. It proved to be adequate, as can be seen in the paper by Campanella et al in this issue, but incomplete and not 
TABLE 1

List of Patients Examined

Number of

Type of Ataxia

Subjects Examined

Genetics

Ethnic Origin

1. Friedreich's Ataxia

2. Ataxia of Beauce

3. Sanger-Brown cerebellar atrophy

4. O.P.C.A. (Wyoming type)

5. O.P.C.A. (Matane type)

6. O.P.C.A. (Schut-Swier type)

- at risk subjects

- ataxic subjects
5

10

7. O.P.C.A. (Gaspésie type)

\begin{tabular}{ll} 
& 20 \\
\hline TOTAL & 47
\end{tabular}

Recessive

Recessive

Dominant

Dominant

Recessive

Dominant

French canadian

French canadian

Scandinavian

Anglosaxon

French canadian

Dutch

Dominant

French canadian sufficiently discriminative. For example, some items are scored on a $0-2$ scale, and others on a $0-4$ scale, making it difficult to function in the field, without the criteria master sheet. Moreover, some items of importance in the diagnosis of certain forms of ataxia are not included, such as muscle strength, pes cavus, scoliosis, postural tremor. We were forced to add copious notes to the recording sheets to reflect the complete picture.

For all these reasons we decided to prepare a new standardized grading form (Tables 3 and 4) which permits a discriminant analysis of major subscores: cranial nerves, coordination, tone, reflexes, peripheral signs and muscle strength. Criteria and definitions are listed in Table. 5. It should be noted that all scores are graded on a scale of $0-3$ which is probably the one offering the most familiarity to the clinician: slight, moderate and severe disability or deviation from normal. The 47 patients in our study were thus graded and the averaged results are given in Table 6 . It can be seen that there was a significant positive correlation between the total ataxia score and functional stages. A more detailed analysis of each sub-score (not reported here for lack of space but to be included in a thesis by E.P.) would reveal for example that OPCA patients have high coordination and tone scores while Friedreich's ataxia patients have very high ataxia scores coupled with maximal deviation from normal (decrease) in the tendon reflex score, severe muscle weakness scores

TABLE 2

Functional Staging of Ataxia

STAGE 0: Normal in at-risk subject.

STAGE I: Patient with minimal signs detected during family screening, but previously undetected and unsuspected by patient.

STAGE II: Symptoms present, recognized by patient, but still mild. The patient is physically capable of leading an independent life, but work activities can be somewhat restricted.

STAGE III: Symptoms are completely developed. The patient needs help or aids to move about and transfer.

STAGE IV: Patient is confined to wheel chair.

STAGE V: Patient is confined to bed.

(Table 7), and marked peripheral signs scores.

We feel that this scoring and staging system is an easy, workable and reproducible scheme for objectively grading the disability of an ataxic patient, even under field conditions. We plan to use this scheme in a series of pharmacologic trials to be undertaken shortly.

\section{ACKNOWLEDGMENTS}

These studies were made possible by a grant from "Association Canadienne de l'Ataxie de Friedreich". The authors would particularly like to thank Dr. Larry Schut and the National Ataxia Foundation of Minneapolis for their generous hospitality and cooperation.

\section{REFERENCES}

BARBEAU, A. (1980). Distribution of ataxia in Quebec in: Spinocerebellar Degenerations (ed. Japan Medical Research Found.) Univ. Tokyo Press, Tokyo, pp. 121-142.

DE FALCO, F.A.; MANSI, D; VENTOLA, F.; FILLA, A. and CAMPANELLA, G. (1979). Proposta di une scheda di rileva- mento clinico delle eredoatassie spinocerebellari. Acta Neurol., Quaderno 39, 103109.

GEOFFROY, G.; BARBEAU, A.; BRETON, G.; LEMIEUX, B.; AUBÉ, M.; LÉGER, C. and BOUCHARD, J.P. (1976). Clinical Description and Roentgenologic Evaluation of Patients with Friedreich's Ataxia. Can. J. Neurol. Sci., 3: 279-286.

HOEHN, N.M. and YAHR, M.D. (1967). Parkinsonism: onset, progression and mortality. Neurology 17: 427-442.

KONIGSMARK, G. and WEINER, L. (1970). The olivo-ponto-cerebellar atrophies. A review. Medicine, 49: 227-241.

LANDIS, D.M.D.; ROSENBERG, R.N.; LANDIS, S.C.; SCHUT, L. and NYHAN, W.L. (1974). Olivo-ponto-cerebellar Degeneration. Clinical and ultra-structural abnormalities. Arch. Neurol. 31: 295-307.

SCHUT, J. (1950). Hereditary ataxia: clinical study through six generations. Arch. Neurol. Psychiarry 63: 535-568.

WASTIAUX, J.P.; LAMOUREUX, G,; BOUCHARD, J.P.; DURIVAGE, A.; BARBEAU, C. and BARBEAU, A. (1978). HLA and complement typing in olivo-pontocerebellar atrophy. Can. J. Neurol. Sci. 5: 7581. 
TABLE 3

Ataxia Clinical Rating Scale

\section{A. IDENTIFICATION}

Name:

Address:

Date exam:

Treating physician:

Examiner:

Chart No:

B. EVOLUTION

Present age:

Age at onset of symptoms:

Known heredity:

Handedness:

Sex:

\section{DIAGRAM OF SPIRAL}

(right and left hand)

\begin{tabular}{|c|c|c|c|c|c|c|c|c|c|c|}
\hline $\begin{array}{l}\text { D. SUB-SCORES } \\
\text { FUNCTIONAL } \\
\text { STAGE }\end{array}$ & Heredity & $\begin{array}{c}\text { Age } \\
\text { Onset }\end{array}$ & $\begin{array}{c}\text { Duration } \\
\text { illness } \\
\text { (years) }\end{array}$ & $\begin{array}{c}\text { Cranial } \\
\text { nerves }\end{array}$ & Ataxia & Tone & $\begin{array}{c}\text { Re- } \\
\text { flexes }\end{array}$ & $\begin{array}{l}\text { Peri- } \\
\text { pheral }\end{array}$ & $\begin{array}{c}\text { Muscle } \\
\text { str. }\end{array}$ & $\begin{array}{l}\text { Total } \\
\text { Score }\end{array}$ \\
\hline & & & & & & $+1-$ & $+1-$ & & & MAX. 138 \\
\hline E. & CODING & & & & & $\overline{\text { FII }}$ & L DIA & NOSIS & & \\
\hline
\end{tabular}

TABLE 4

Ataxia Clinical Rating Scale

All items on $0-3$ scale: $0: N$; : Mild; 2: Moderate; 3: Severe disability Items Score Items

A.

1. Speech

2. Nystagmus

3. Eye movements

4. Fundi

5. Tongue changes

6. Cough

\begin{tabular}{lc}
\hline SUB-SCORE (C.N.) & MAX \\
& 18 \\
\hline
\end{tabular}

B. COORDINATION
7. Normal gait
8. Tandem gait
9. Romberg
10. Finger to nose - right
11. Finger to nose - left
12. Heel to knee - right
13. Heel to knee - left
14. Spiral - right
15. Spiral - left
16. Adiadocokinesia - right
17. Adiadocokinesia - left
18. Tapping - right hand
19. Tapping - left hand
20. Postural tremor

\begin{tabular}{lc}
\hline SUB-SCORE (AT) & MAX \\
& 42 \\
\hline
\end{tabular}


C. TONE (deviation from $\mathrm{N}$.)

21. Tone - right arm

22. Tone - left arm

23. Tone - right leg

24. Tone - left leg

25. Holmes test - right

26. Holmes test - left

\begin{tabular}{lc}
\hline SUB-SCORE (T) & MAX \\
& 18 \\
\hline
\end{tabular}

E. PERIPHERAL SIGNS

35. Atrophy upper limbs

36. Atrophy lower limbs

37. Fasciculations

38. Myoclonias

39. Pes cavus

40. Scoliosis

41. Vibrations - right (secs)

42. Vibrations - left (secs)

SUB-SCORE (P.S.) MAX

+/- D. REFLEXES (deviation from N.)

$+1-$

27. DTR - right biceps

28. DTR - left biceps

29. DTR - right knee

30. DTR - left knee

31. DTR - right achil.

32. DTR - left achil.

33. Babinski - right

34. Babinski - left

\begin{tabular}{lc}
\hline SUB-SCORE (R) & MAX \\
& 24 \\
\hline
\end{tabular}

\section{F. MUSCLE STRENGTH DECREASE}

43. Right arm

44. Left arm

45. Right leg

46. Left leg

SUB-SCORE (MS) MAX

TABLE 5

Ataxia Clinical Rating Scale Criteria and Definitions

GENERAL NOTES: Unless otherwise indicated, all items are coded on a 0 to 3 scale where

0 : normal

1: mild disability or deviation from normal

2: moderate disability or deviation from normal

3: severe disability or deviation from normal

SPECIFIC CRITERIA (Number corresponds to item; items not quoted, see above):

Item Title Grades

2.

3.

4.

5.

6.

1. fine lateral nystagmus

2. clear lateral $+/$ - upward gaze nystagmus

3. spontaneous nystagmus

1. smooth but slow pursuit (viscosity)

2. saccadic or irregular pursuit

3. paralysis in one or more directions

1. slight temporal palor

2. retinitis $+/$ - optic atrophy

3. macular or retinal degeneration + optic atrophy

1. fasciculations alone

2. fasciculations + slight atrophy

3. marked atrophy + limitation movements

1. hesitation in 3 consecutive coughs

2. dyspnea and arrest in consc. coughs

3. unable to do test 
7,8

9.

$16,17$.

20.

D.

25,26 .

33, 34.

37.

38.

39.

40.

$41,42$.

$43,44,45,46$.
NORMAL GAIT/TANDEM

ROMBERG

“TEST DES MARIONETTES"

POSTURAL TREMOR

TONE \& REFLEXES

HOLMES TEST

BABINSKI TEST

FASCICULATIONS

MYOCLONIAS

2. myoclonias bilateral, occasional

FEET

SCOLIOSIS

VIBRATIONS

MUSCLE STRENGTH
1. dysbalance but gait without support

2. dysbalance but needs support

3. gait or tandem impossible

1. some oscillations eyes closed

2. oscillations eyes open

3. manoeuvre impossible

1. fine hand tremor (extended arm)

2. marked hand tremor

3. hand, trunk and hand tremor

To be scored as deviation from normal (mild, moderate, severe) with direction indicated: increased: $+;$ decreased: $-;$ (absent is scored as -3 ; presence of clonus implies +3 )

0 . normal braking

1. braking present but delayed

2. arms hits examiner's protecting arm

3. arm would slap face or thorax without protection

1. no response to test (indifferent)

2. fanning of toes alone

3. fanning and slow big toe retraction

1. rare fasciculations

2. localized but frequent fasciculations

3. generalized fasciculations

1. rare myoclonias, unilateral

3. continuous myoclonias

1. high arches

2. definite pes cavus

3. pes cavus + toe deformities

1. scoliosis $0-10^{\circ}$

2. scoliosis $10-30^{\circ}$

3. scoliosis $>30^{\circ}$

Taken with $128 \mathrm{cps}$ tuning-fork at external malleolus
0.11 or more secs
1. 8 - 11 secs
2. $5-8$ secs
3. $<5$ secs

1. weakness upon testing only

2. difficulty in maintaining posture or resisting a pull

3. total paralysis

TABLE 6

Ataxia Clinical Rating Results

\begin{tabular}{ccccc}
\hline Functional Stage & $\mathbf{n}$ & Mean Total Score & \pm S.E.M. & Range \\
\hline 0 (at risk) & 5 & 4.4 & 1.2 & $0-7$ \\
1 & 7 & 13.0 & 1.2 & $9-17$ \\
2 & 13 & 41.0 & 1.9 & $31-54$ \\
3 & 11 & 67.9 & 3.8 & $51-88$ \\
4 & 11 & 84.1 & 4.9 & $54-107$ \\
\hline
\end{tabular}


TABLE 7

Mean Scores in Various Forms of Ataxia (mean $\pm S E M)$

\begin{tabular}{|c|c|c|c|c|}
\hline No. of ataxic patients & $\begin{array}{c}\text { OPCA (Gaspé) } \\
20\end{array}$ & $\begin{array}{c}\text { OPCA (Minn.) } \\
10\end{array}$ & $\begin{array}{c}\text { Friedreich's } \\
4\end{array}$ & $\begin{array}{c}\text { Beauce } \\
3\end{array}$ \\
\hline mean age of onset & $30.1 \pm 3.1$ & $20.6 \pm 1.7$ & $15.7 \pm 0.9$ & $17.7 \pm 3.8$ \\
\hline duration of illness (yrs) & $13.6 \pm 2.1$ & $3.2 \pm 0.8$ & $16.0 \pm 1.6$ & $24.0 \pm 8.5$ \\
\hline cranial nerve defects & $3.5 \pm 0.5$ & $4.9 \pm 1.1$ & $7.5 \pm 1.9$ & $4.0 \pm 0.6$ \\
\hline coordination defects & $24.4 \pm 2.0$ & $15.2 \pm 3.9$ & $29.5 \pm 2.1$ & $29.7 \pm 4.3$ \\
\hline muscle tone changes & $7.4 \pm 1.0$ & $9.1 \pm 1.0$ & $10.5 \pm 1.3$ & $10.7 \pm 4.4$ \\
\hline changes in reflexes & $10.9 \pm 1.5$ & $8.9 \pm 1.9$ & $24.0 \pm 0.0$ & $13.3 \pm 3.4$ \\
\hline peripheral signs & $3.5 \pm 0.9$ & $0.8 \pm 0.3$ & $11.7 \pm 0.7$ & $7.7 \pm 5.0$ \\
\hline muscle strength changes & $2.7 \pm 0.8$ & $1.5 \pm 0.9$ & $8.5 \pm 1.0$ & $4.7 \pm 2.9$ \\
\hline
\end{tabular}

